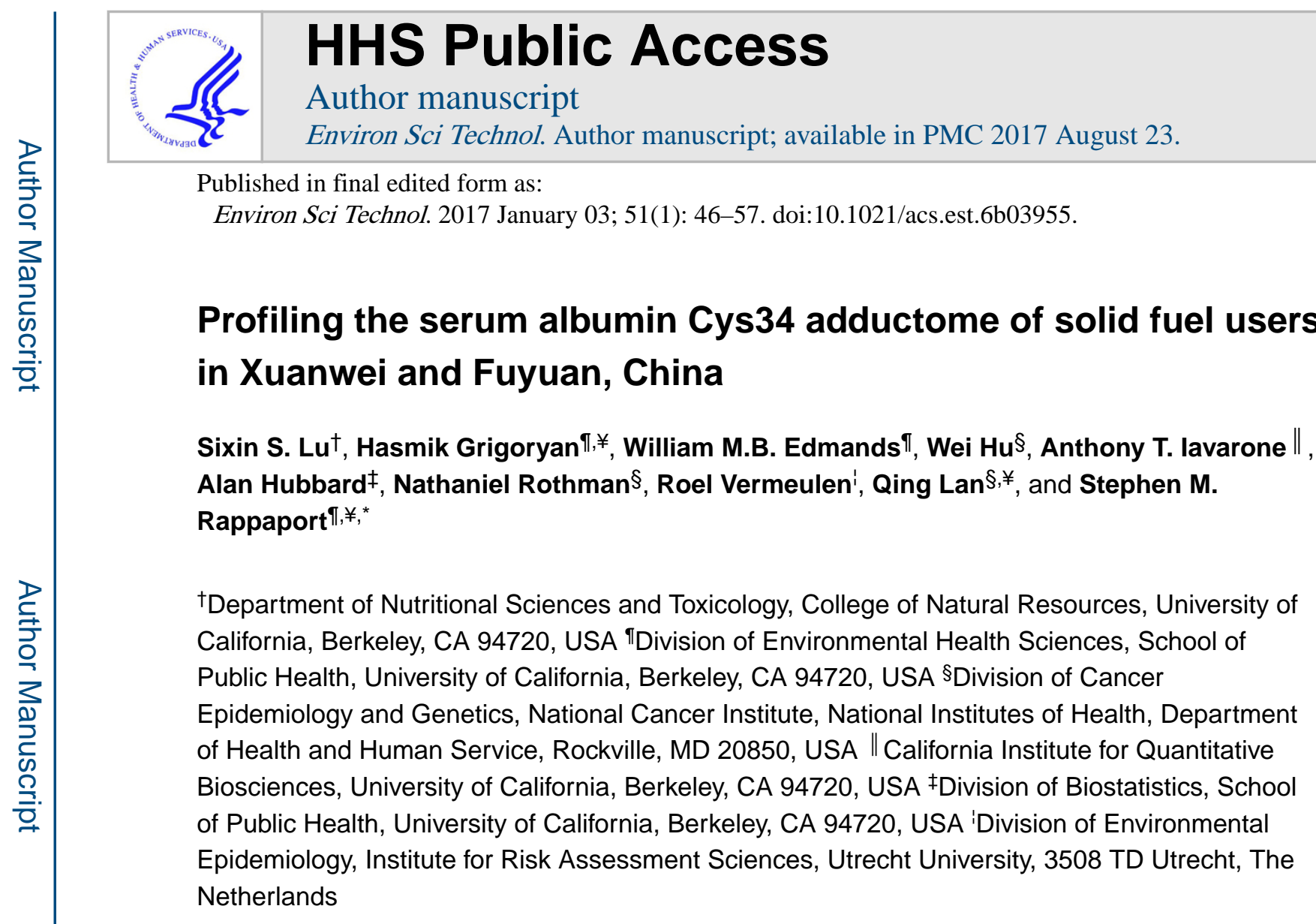

\title{
Abstract
}

\begin{abstract}
Xuanwei and Fuyuan counties in China have the highest lung cancer rates in the world due to household air pollution from combustion of smoky coal for cooking and heating. To discover potential biomarkers of indoor combustion products, we profiled adducts at the Cys34 locus of human serum albumin (HSA) in 29 nonsmoking Xuanwei and Fuyuan females who used smoky coal, smokeless coal or wood, and 10 local controls who used electricity or gas fuel. Our untargeted 'adductomics' method detected 50 tryptic peptides of HSA, containing Cys 34 and prominent post-translational modifications. Putative adducts included Cys34 oxidation products, mixed disulfides, rearrangements and truncations. The most significant differences in adduct levels across fuel types were observed for $S$-glutathione ( $S$-GSH) and $S$ - $\gamma$-glutamylcysteine ( $S$ - $\gamma$ GluCys), both of which were present at lower levels in subjects exposed to combustion products than in controls. After adjustment for age and personal measurements of airborne benzo(a)pyrene, the largest reductions in levels of $S$-GSH and $S$ - $\gamma$-GluCys relative to controls were observed for users of smoky coal, compared to users of smokeless coal and wood. These results point to possible depletion of GSH, an essential antioxidant, and its precursor $\gamma$-GluCys in nonsmoking females exposed to indoor-combustion products in Xuanwei and Fuyuan, China.
\end{abstract}

\footnotetext{
"Corresponding author: Prof. S. M. Rappaport, Center for Exposure Biology, School of Public Health, University of California, Berkeley, CA 94720, USA. Tel: 510-642-4255. Fax: 510-642-5815. srappaport@berkeley.edu.

$¥$ Author Contributions

These authors co-supervised this work.

Notes

The authors declare no competing financial interest.

SUPPORTING INFORMATION AVAILABLE

This information is available free of charge via the Internet at http://pubs.acs.org:
} 


\section{TOC only}

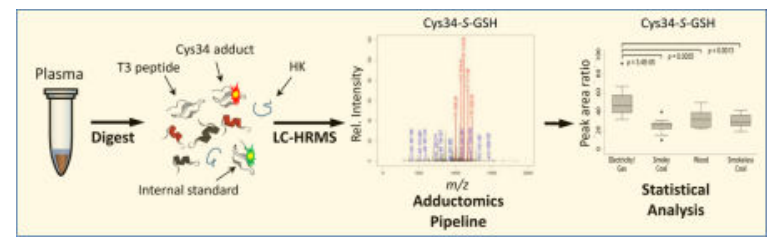

\section{Keywords}

smoky coal; Xuanwei; lung cancer; PAH; HSA; Cys34; protein adductomics; mass spectrometry

\section{Introduction}

Lung cancer is the leading cause of cancer mortality worldwide. ${ }^{1}$ While most lung cancers can be attributed to cigarette smoking, in East Asia an estimated $61 \%$ of female lung cancers are observed in never-smokers ${ }^{2}$, especially those exposed to household air pollution from coal combustion. ${ }^{3}$ Domestic fuel combustion has been recognized as a major source of exposure to carcinogens that affects about 3 billion people worldwide. ${ }^{4}$ Indeed, Xuanwei and Fuyuan Counties in China, where smoky (bituminous) coal is used for domestic cooking and heating, have the highest lung cancer incidence and mortality in the world. 5,6

Since women from Xuanwei and Fuyuan rarely smoke, the high incidence of lung cancer has motivated scrutiny of possible risk factors. Nonsmoking Xuanwei women, who use smoky coal, have a 30-fold greater risk of lung cancer than those who use smokeless (anthracite) coal or wood. ${ }^{7}$ Compared to smokeless coal, smoky coal emits significantly more particulate matter (PM), polycyclic aromatic hydrocarbons (PAHs) and silica, all of which are known lung carcinogens. ${ }^{6,}{ }^{8-10}$ Of these potentially causal exposures in Xuanwei, PAHs have been scrutinized, based on detection of PAH-DNA adducts, ${ }^{11}$ characteristic mutational spectra in lung tumors, ${ }^{12}$ and risk modulation by genes involved in PAH metabolism. ${ }^{13,14}$ However, the heterogeneity of emissions of PAHs and other combustion products, even across subtypes of smoky coal has complicated analysis of exposure-response relationships. ${ }^{7-10}$

Many environmental toxicants that emanate from combustion of solid fuels are either reactive electrophiles or are metabolized to such species in the body. Reactive electrophiles can produce DNA mutations and modify functional proteins ${ }^{15,16}$ and can alter the redox proteome. ${ }^{17}$ Since reactive electrophiles have short lifetimes, investigators have studied their dispositions in vivo by measuring adducts from reactions with abundant proteins in the blood, mainly hemoglobin and human serum albumin (HSA). ${ }^{18} \mathrm{HSA}$ is particularly interesting because it contains a nucleophilic hotspot, Cys34, that efficiently scavenges reactive oxygen species (ROS) and other small electrophiles in serum, where it represents about $80 \%$ of the antioxidant capacity. ${ }^{19}$ Oxidation of Cys 34 to the reactive sulfenic acid (Cys34-SOH), can lead to formation of mixed Cys34-disulfides from reactions between Cys34-SOH and circulating low-molecular-weight thiols. ${ }^{20}$ These Cys 34 disulfides 
represent potential biomarkers of the redox state of the serum over the 1-month residence time of HSA. ${ }^{21,22}$

Our laboratory has recently developed an untargeted assay for characterizing modifications at the Cys34 locus of HSA that we refer to as 'Cys34 adductomics'. ${ }^{23}$ The scheme focuses on the third largest tryptic peptide of HSA ('T3') with sequence ALVLIAFAQYLQQC ${ }^{34}$ PFEDHVK and a mass of 2,432 Da. Adducts of this hydrophobic peptide are separated by nanoflow liquid chromatography (nLC) and detected by highresolution mass spectrometry (HRMS). A bioinformatic pipeline is used to locate T3 modifications from tandem MS2 spectra, to annotate modifications based on accurate masses, and to quantitate and normalize peak areas.

Given the constellation of electrophiles generated during combustion of fossil fuels, it is difficult to hypothesize about particular adducts or classes of protein modifications that might be observed in blood from Xuanwei and Fuyuan subjects. Cys34 adductomics offers a data-driven approach for comparing adduct features across populations differentially exposed to combustion effluents and thereby for discovering potential biomarkers of relevance to human health. Discriminating adduct features can be identified and targeted for follow-up studies to investigate effects of exposure and to develop mechanistic understanding. Here, we describe application of our methodology to characterize Cys34 adducts in plasma from 29 healthy nonsmoking women from Xuanwei and Fuyuan, China, who used smoky coal, smokeless coal or wood, and 10 local controls who used electricity/ gas. We detected 50 T3-derived peptides in these women, and explored relationships between adduct levels and the types of solid fuel as well as personal measurements of airborne PM and a carcinogenic PAH (benzo(a)pyrene, BaP). Despite the small sample sizes, we detected several highly-significant associations between adduct levels and covariates that should generate hypotheses for follow-up studies.

\section{Experimental Section}

\section{Reagents}

Acetonitrile (LC/MS grade), dimethyl sulfoxide, ethylenediaminetetraacetic acid, triethylammonium bicarbonate buffer $(1 \mathrm{M}$ ) and trypsin (from porcine pancreas, catalog number T0303) were from Sigma-Aldrich (St. Louis, MO). Formic acid and methanol were from Fisher Scientific (Optima LC/MS, Fair Lawn, NJ). Water (18.2 $\mathrm{m} \Omega \mathrm{cm}$ resistivity at $25^{\circ} \mathrm{C}$ ) was purified by a PureLab Classic system (ELGA LabWater, Woodridge, IL). Isotopically labeled T3 peptide (iT3) with sequence $\mathrm{AL}-\left[{ }^{15} N,{ }^{13} C\right.$-Val]LIAFAQYLQQCPFEDH- $\left[{ }^{15} N,{ }^{13} C\right.$-Val]-K was custom-made (>95\%, BioMer Technology, Pleasanton, CA). The carbamidomethylated iT3 peptide (IAA-iT3) was used as an internal standard for monitoring mass and retention time (RT) stabilities and was prepared as reported previously. ${ }^{24}$

\section{Plasma samples and air measurements}

Plasma samples were obtained with informed consent from subjects in China under protocols approved by the National Cancer Institute and local Chinese institutions. Plasma 
from 29 nonsmoking female subjects using smoky coal, smokeless coal or wood (hereafter, "exposed subjects") was collected in 2008 and 2009 as part of a cross sectional study in Xuanwei and Fuyuan counties, China. Details of this study, including the demographic characteristics of the subjects and collection of air and biological samples have been described $^{8-10,25,26}$. Blinded duplicate aliquots from four exposed subjects were also included to assess sample-processing variability and quality assurance, resulting in a total of 33 plasma samples from exposed subjects. Archived plasma from 10 nonsmoking female electricity or gas users (hereafter, "control subjects"), were collected between 2007 and 2010 in nearby hospitals in Fuyuan, Qujing, and Xuanwei Counties. Control subjects were being treated for conditions unrelated to tobacco smoking, smoky coal use, and lung disease and had the same age distribution as exposed subjects. Plasma samples were stored at $-80{ }^{\circ} \mathrm{C}$ for 4-8 years before analysis.

Personal $\mathrm{PM}_{2.5}$ samples (i.e. $\mathrm{PM}$ with aerodynamic diameter less than $2.5 \mu \mathrm{m}$ ) were collected on Teflon filters for all exposed subjects in the 24-hr period prior to blood draw. ${ }^{8,9}$ Nineteen of these samples were extracted with dichloromethane and analyzed for $\mathrm{BaP}$ by gas chromatography-mass spectrometry. ${ }^{9}$ Exposed subjects for whom $\mathrm{BaP}$ exposures were not measured were imputed the median BaP levels estimated among other subjects with the same type of fuel. Three categories of $\mathrm{BaP}$ and $\mathrm{PM}_{2.5}$ exposures were established as follows: controls, low exposure (below the median value) or high exposure (at or above the median value) (median values: $\mathrm{BaP}=36.7 \mathrm{ng} / \mathrm{m}^{3}, \mathrm{PM}_{2.5}=145 \mu \mathrm{g} / \mathrm{m}^{3}$ ). Personal $\mathrm{BaP}$ and $\mathrm{PM}_{2.5}$ levels for the 10 control subjects were imputed the minimum values observed in any exposed subject divided by $\sqrt{2}$.

Table S1 (Supporting Information) provides summary statistics for selected variables - age, BMI, and concentrations of $\mathrm{BaP}$ and PM2.5 - across the 39 subjects stratified by fuel type.

\section{Sample processing}

The 43 plasma samples were processed in four random batches of 10 or 11 samples. Samples were analyzed as previously described. ${ }^{23}$ Briefly, $5 \mu \mathrm{L}$ of plasma was mixed with $60 \mu \mathrm{L}$ of $50 \%$ methanol for $15 \mathrm{~min}$ and centrifuged. Fifty $\mu \mathrm{L}$ of the supernatant was mixed with $200 \mu \mathrm{L}$ of digestion buffer $(50 \mathrm{mM}$ triethylammonium bicarbonate, $1 \mathrm{mM}$ ethylenediaminetetraacetic acid, $\mathrm{pH} 8.0$ ) and stored at $-80{ }^{\circ} \mathrm{C}$ prior to digestion. One hundred thirty-eight microliters of the solution were transferred to a MicroTube (MT-96, Pressure Biosciences Inc., South Easton, MA) to which $2 \mu \mathrm{L}$ of $10 \mu \mathrm{g} / \mu \mathrm{L}$ trypsin was added ( 1:10 ratio of trypsin:protein, w/w). The tube was capped (MC150-96, Pressure Biosciences Inc.), vortexed briefly, and placed in a pressurized system (Barocycler NEP2320, Pressure Biosciences Inc.) that cycled between 1,380 bar (45 s) and ambient pressure ( $15 \mathrm{~s}$ ) for $30 \mathrm{~min}$ at $37{ }^{\circ} \mathrm{C}$. We had previously shown that pressure cycling of serum/plasma extracts containing 10-20\% methanol promoted rapid tryptic digestion, even without prior reduction of disulfide bonds in HSA. ${ }^{23}$ After digestion, $3 \mu \mathrm{L}$ of $10 \%$ formic acid was added to stop digestion, and the digest was briefly vortexed and centrifuged to remove particles. Twenty microliters of the digest and $1 \mu \mathrm{L}$ of a $20 \mathrm{pmol} / \mu \mathrm{L}$ solution of internal standard (IAA-iT3) were transferred to a silanized autosampler vial containing 79 
$\mu \mathrm{L}$ of an aqueous solution of $2 \%$ acetonitrile and $0.1 \%$ formic acid. The diluted digest was stored at $-80{ }^{\circ} \mathrm{C}$ and/or queued at $4{ }^{\circ} \mathrm{C}$ for up to $36 \mathrm{~h}$ prior to analysis by nLC-HRMS.

\section{Nanoflow liquid chromatography-mass spectrometry}

Digests were analyzed by nLC-HRMS with an LTQ Orbitrap XL Hybrid mass spectrometer coupled to a Dionex UltiMate ${ }^{\circledR} 3000 \mathrm{nLC}$ system via a Flex Ion nano-electrospray ionization source (Thermo Fisher Scientific, Waltham, MA), operated in positive ion mode, as described previously. ${ }^{23}$ Briefly, duplicate $1-\mu \mathrm{L}$ portions of each diluted digest were injected into the $\mathrm{nLC}$ and separated on a Dionex PepSwift monolithic column $(100-\mu \mathrm{m}$ i.d. $\times$ $25 \mathrm{~cm}$ ) (Thermo Scientific, Sunnyvale, CA, USA). Full scan MS spectra $(\mathrm{m} / \mathrm{z} 350-1200)$ were acquired with a resolution of 60,000 at $\mathrm{m} / \mathrm{z} 400$ in the Orbitrap. In data-dependent mode, up to six intense triply-charged precursor ions from each MS1 scan were fragmented by collision-induced dissociation and tandem mass spectra (MS2) were acquired in the linear ion trap. The column was washed after every pair of duplicate injections with $1 \mu \mathrm{L}$ of a solution containing $80 \%$ acetonitrile, $10 \%$ acetic acid, 5\% dimethyl sulfoxide and 5\% water.

\section{Locating T3-related peptides with MS2 spectra}

As described previously, ${ }^{23}$ RAW data files were converted to mzXML format using the ProteoWizard msConvert tool $(3.06387,64-b i t)^{27}$ without filters. All MS2 spectra collected in the elution window between 20 and 35 min were screened for putative adducts using inhouse software written in R. ${ }^{28}$ Briefly, the screening algorithm focused on signature ions from the T3 peptide and required the presence of at least five unmodified $b^{+}$-series fragment ions with signal-to-noise ratios $>3: b_{3}{ }^{+}-b_{6}{ }^{+}$, and $b_{11}{ }^{+}-b_{13}{ }^{+}$, plus a set of at least four fragment ions indicative of the prominent $y_{14}{ }^{2+}$ through $y_{18}{ }^{2+}$ ions with relative intensities $z$ $20 \%$ of the base peak. Spectra that passed the screening algorithm were considered to represent T3-related peptides. These T3 peptides were then clustered with each nearest neighbor having a monoisotopic mass (MIM)within $0.003 \mathrm{~m} / \mathrm{z}$ and a RT within $0.4 \mathrm{~min}$. For each group, an isotope distribution consistent with its respective triply-charged precursor MIM was verified, and the means of MIMs and RTs were calculated. Representative MS2 spectra of all putative T3 adducts are shown in Figure S1 (Supporting Information).

\section{Annotation of Putative Adducts}

Putative T3 adducts were annotated as described previously. ${ }^{23}$ Briefly, the masses added to the thiolate form of the T3 peptide $\left(\mathrm{Cys} 34-\mathrm{S}^{-}\right)$were calculated and plausible elemental compositions were probed or confirmed using ChemCalc Molecular Formula finder, ${ }^{29}$ Molecular Weight Calculator (version 6.50, http://www.alchemistmatt.com/), UNIMOD (http://www.unimod.org/) and MetFrag. ${ }^{30}$ Mass accuracy of the assigned elemental composition was assessed in terms of the difference $(<3 \mathrm{ppm})$ between theoretical and observed MIMs. A modification at Cys34 is indicated by MS2 spectra displaying unmodified $y_{7}^{+}$or $y_{7}^{2+}$ (i.e. from Pro35 to the C-terminus) plus mass-shifted $b_{14}{ }^{+}$(i.e. from the $\mathrm{N}$-terminus to Cys34), $y_{8}{ }^{+}$or $y_{8}{ }^{2+}$ (i.e. from Cys34 to the C-terminus). Conversely, the presence of unmodified $b_{14}{ }^{+}, y_{8}{ }^{+}$and $y_{8}{ }^{2+}$ indicates that modification(s) were not at Cys $34 .{ }^{23}$ Adducts lacking unambiguous diagnostic ions were annotated as having unclear modification sites. Evidence for annotations is given in Table S2 (Supporting Information). 


\section{Quantitation of T3-related peptides}

Automated peak integration of T3-related peptides was performed using Processing Methods in Xcalibur software (version 2.0.7 SP1, Thermo Fisher Scientific, Inc., Waltham, MA) based on MIMs and RTs with 5 ppm mass accuracy using the Genesis algorithm without smoothing and with $>3$ signal-to-noise ratio. Each low-abundance peak of a putative T3 peptide was verified by comparing the observed isotopic pattern against the expected pattern. To quantitate and adjust adduct levels for the amounts of HSA in individual digests, peak areas were divided by the corresponding peak areas of a "housekeeping peptide" (HK), with sequence LVNEVTEFA, that appears as a doubly-charged peptide (MIM $=575.31113$ $\mathrm{m} / \mathrm{Z}$, average $\mathrm{RT}=13.5 \mathrm{~min}$ ). The peak area ratio (PAR, adduct peak area/HK peak area) was previously shown to be a robust linear predictor of adduct concentrations over at least a 500-fold range $(0.01-5 \mu \mathrm{M}){ }^{23}$ Approximate adduct concentrations with units of pmol adduct/mg HSA were estimated as previously described. ${ }^{23}$

\section{Batch Adjustment}

Peak-area ratios were log-transformed and adjusted for batch effects with a mixed-effects model similar to that described previously, ${ }^{23}$ using Stata software (Stata Statistical Software: Release 13. College Station, TX). Since data included four blinded sample replicates as well as injection replicates for all samples, the following model was used:

$$
\ln \left(\frac{\text { Adduct }}{H K \text { peptide }}\right)=\beta_{0}+\beta_{1_{i}}+\mu_{0_{j}}+\mu_{1_{j k}}+\varepsilon_{i j k h}
$$

where $\beta_{0}$ is the fixed overall mean value of the logged peak-area ratio (intercept), $\beta_{1_{i}}$ is the fixed effect for the $I^{\text {th }}$ batch, $\mu_{0_{j}}$ is the random effect for the $f^{\text {th }}$ subject, $\mu_{1_{j k}}$ is the random effect for the $k^{\text {th }}$ replicate sample from the $j^{\text {th }}$ subject (duplicate samples from four subjects), and $\varepsilon_{i j k h}$ is the residual error for the $h^{\text {th }}$ injection for a given sample (duplicate injections for all subjects). Restricted maximum likelihood (REML) estimation was used to fit the models. Coefficients of variation (CVs), representing sample replicates and duplicate injections were

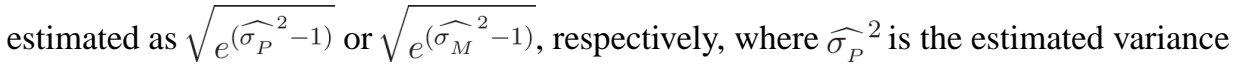
component for replicate samples and ${\widehat{\sigma_{M}}}^{2}$ is the estimated variance component for replicate injections. Intraclass correlation coefficients (ICCs) were estimated as

$I C C=\frac{{\widehat{\sigma_{B}}}^{2}}{{\widehat{\sigma_{B}}}^{2}+{\widehat{\sigma_{P}}}^{2}+{\widehat{\sigma_{M}}}^{2}}$, where ${\widehat{\sigma_{B}}}^{2}$ is the estimated between-subject variance component. Adducts whose models failed to fit $(n=2)$ or with ICCs $<0.1(n=12)$ were eliminated from statistical testing; however each of their median levels was estimated across subjects with PARs.

After batch adjustment with model [1], subject-specific PARs were predicted as $\ln (P A R)=\beta_{0}+\mu_{0_{j}}$ for each adduct ${ }^{23}$ and these values were used for statistical tests. When a given adduct was not detected in all replicates from a given subject, the $\ln (\mathrm{PAR})$ was imputed a value of minimum $-\ln (\sqrt{2})$ where minimum is the smallest $\ln (\mathrm{PAR})$ of a given 
adduct observed in any subject. Among 36 adducts with $I C C s \geq 0.1,11$ had between one and 39 non-detected values $($ median $=15)$.

Four sets of structurally-related adducts were collapsed into clusters, namely, two peaks of $S$-homocysteine ( $S$-hCys), and the respective sodium and/or potassium adducts of unadducted T3, $S$-cysteine ( $S$-Cys) and $S$-cysteinylglycine ( $S$-CysGly). For each cluster, predicted subject-specific logged adduct levels were exponentiated, summed, and logtransformed. After clustering, 32 adducts and clusters were subjected to statistical analyses.

\section{Statistical Analyses}

Statistical analyses were performed with Stata software using predicted logged PARs from model [1] ( $\times 10,000$ for scaling) for each of the 32 adducts and clusters. Three permutation Kruskal-Wallis tests were performed using the permute command of Stata with 100,000 replications, under the null hypotheses that fuel types, $\mathrm{BaP}$ categories or $\mathrm{PM}_{2.5}$ categories had the same median adduct levels. Significance levels were corrected for multiple testing at a 5\% uncorrected false discovery rate (FDR) using the simes option (Benjamini-Hochberg method $)^{31}$ of the multproc program. ${ }^{32}$ For each significant Kruskal-Wallis test, a Wilcoxon rank sum test was performed between all pairs of exposure categories with the dunntest package $^{33}$ with significance levels corrected at 5\% FDR using the simes option. Adducts with absolute values of Spearman correlation coefficients $\left(r_{S}\right)$ greater than 0.5 were organized into a network generated with Cytoscape. ${ }^{34}$ Multivariable linear regression was used to model each adduct or cluster as a function of the fuel types (as dichotomous variables) plus age and log-transformed levels of $\mathrm{BaP}$ as covariates. Exploratory analyses, using backward stepwise elimination, revealed that $\mathrm{BMI}$ and $\mathrm{PM}_{2.5}$ were weaker predictors than fuel groups, $\mathrm{BaP}$ and age, and thus were not included in the multivariable models for power considerations.

\section{RESULTS}

\section{Annotation of Adducts}

The adductomics workflow identified 50 distinct T3-related peptides (numbered M1 through M50) as summarized in Table 1. Median adduct levels spanned a 19,500-fold range with PARs ranging from 0.19 to 3,640, corresponding to approximate adducts concentrations of 0.080 to $1,590 \mathrm{pmol} / \mathrm{mg}$ HSA. For 43 of the T3 peptides, the observed MIM was within 3 ppm of the theoretical value of a modification having a plausible elemental composition. Previously-reported modifications ${ }^{23}$ include truncations (M1-M4), a labile adduct (M5), unmodified T3 (M6), the T3 dimer (M7, 6+ charge state), T3 methylation at a site other than Cys34 (M9), and Cys34 oxidation products (M8, M11 and M14). The largest class of modifications consisted of 22 mixed disulfides of Cys34, most of which have been reported, ${ }^{23}$ including two isomeric modifications of $S$-hCys (M28 and M29), four Na and K adducts of $S$-Cys and $S$-CysGly (M31, M33, M40 and M41), and two apparent modifications of $S$-hCys or $S$-CysGly (M32 and M38). Other putative adducts that have not been reported previously include: $S$-methylthiolation (M13), a Cys34 adduct of pyruvate or malonate semialdehyde (M16), a variant of the $S$-Cys adduct (M19, possibly $\mathrm{NH}_{2} \rightarrow \mathrm{OH}$, $-\mathrm{H}_{2} \mathrm{O}$ ), a Cys34 adduct of oxindole (M27), and a Cys34 trisulfide, i.e. $S$-S-hCys (M36). 
Evidence used for annotation of all T3-related peptides is summarized in Table S2

(Supporting Information).

\section{Summary Statistics and Global Comparisons}

Median PARs $(\times 10,000)$ and CVs are shown in Table 2 for all adducts or clusters. The levels of Cys34 oxidation products for a given subject always followed the order: sulfinic acid (dioxidation, M11) > Cys34-Gln crosslink (mono-oxidation, M8) >> sulfonic acid (trioxidation, M14), as previously reported for healthy volunteers. ${ }^{23}$ Among 36 adducts with ICCs $\geq 0.1($ ICC median $=0.73$; range: $0.19-0.98), \mathrm{CVs}$ for replicate injections $\left(\mathrm{CV}_{\mathrm{M}}\right.$ : median $=21 \%$; range: $7.7-70 \%$ ) tended to be greater than those for replicate samples $\left(\mathrm{CV}_{\mathrm{P}}\right.$ : median $=5.5 \%$; range: $\left.0-78 \%\right)$.

Table 2 also shows median adduct levels aggregated by fuel type and categories of $\mathrm{BaP}$ and $\mathrm{PM}_{2.5}$ exposures, along with results of Kruskal-Wallis tests that investigated global associations for 32 adducts. After multiple testing correction $(a=0.0078)$, five adducts had significant differences across fuel groups, i.e. the T3 labile adduct (M5), the $S$-hCys cluster (M28+M29), a Cys34 adduct with unknown annotation (M30, likely composition: $+\mathrm{C}_{4} \mathrm{H}_{9} \mathrm{O}_{3} \mathrm{~S}$ ), $S$ - $\gamma$-glutamylcysteine ( $\boldsymbol{S}$ - $\boldsymbol{\gamma}$-GluCys, M43) and $S$-glutathione ( $S$-GSH, M44). The latter three adducts (M30, M43 \& M44) also differed significantly across categories of exposures to both $\mathrm{BaP}$ and $\mathrm{PM}_{2.5}(a=0.0047)$.

\section{Pairwise Differences between Exposure Categories}

The sources of global differences across exposure categories (Table 2) were investigated pairwise with Wilcoxon rank sum tests, several of which had $P$-values that remained significant after corrections for multiple testing. Subjects using electric/gas fuel or smoky coal had significantly lower levels of the T3 labile adduct (M5) than those using wood or smokeless coal (Figure 1A); those using electric/gas fuel or smoky coal had significantly lower levels of $S$-hCys (M28+M29) than those using smokeless coal, while those using electric/gas fuel also had significantly lower levels of $S$-hCys than those using wood (Figure 1B); those using either type of coal had significantly lower levels of $S$ - $\gamma$-GluCys (M43) and $S$-GSH (M44) than those using electric/gas fuel (Figure 1D); and those using each solid fuel had significantly lower levels of a Cys34 adduct with unknown annotation (M30) and $S$ GSH (M44) than those using electric/gas fuel (Figure 1C\&E).

Extending pairwise comparisons to subjects classified by exposures to $\mathrm{BaP}$ and $\mathrm{PM}_{2.5}$, the global differences observed in Table 2 for a Cys34 adduct with unknown annotation (M30), $S$ - $\gamma$-GluCys (M43) and $S$-GSH (M44) reflect significantly higher adduct levels in controls compared to either low- or high-exposed subjects for both BaP and $\mathrm{PM}_{2.5}$ (Figure S2, Supporting Information).

\section{Correlation of Adduct Levels}

Figure 2 shows a correlation map of the 25 adducts having at least one $\left|r_{S}\right|$ greater than 0.5 with another adduct. Many of the moderate to strong correlations were between structurallyor biochemically-related adducts. For example, $S$-GSH (M44) was correlated with $S$ - $\gamma$ GluCys (M43), which in turn was correlated with $S$-Cys (M24). Unadducted T3 (M6) and 
the earlier-eluting $S$-hCys disulfide (M28) were strongly correlated with their methylated counterparts (M9 and M32, respectively). Unadducted T3 (M6), $S$-Cys (M24) and $S$-CysGly (M37) were correlated with their potassium adducts (M12, M33 and M41, respectively). Oxidation products (M8, M11 and M14) were very strongly correlated with each other, as well as with Cys34 truncations (M1 and M3). In fact, the Cys34-Gln crosslink (M8) and sulfinic acid (M11) had the strongest overall correlation $\left(r_{S}=0.95\right)$. Grigoryan et al. ${ }^{24}$ proposed two pathways of crosslink formation between Cys34 and Gln33: from the Cys34 sulfenic acid $(-\mathrm{SOH})$ or from the sulfinic acid $\left(-\mathrm{SO}_{2} \mathrm{H}\right)$, the latter of which is corroborated by our data.

\section{Multivariable Models}

We regressed the log-scale estimates of levels of each of 32 adducts and clusters with sufficient data on the covariates of fuel type, $\ln (\mathrm{BaP})$, and age to identify significant covariate effects and reduce possible confounding (Table 3). Models for 9 adducts (M5, M17, M19, M25, M30, M32, M34, M43 \& M44) contained at least one significant effect with a $P$-value $<0.05$ ( 18 in all). All of the 12 significant effects for fuel group were negative, implying that after adjusting for $\mathrm{BaP}$ and age, use of each solid fuel was typically associated with lower adduct levels than those in controls. On the other hand, all four of the significant BaP effects (M5, M19, M34 \& M44) were positive, indicating that exposure to $\mathrm{BaP}$ increased levels of these adducts after adjusting for fuel type and age. Also, both of the significant effects of age (M17 \& M32) were positive, suggesting that levels of these two adducts increased significantly with age. Only two of the 18 covariate effects with $P$-values $<0.05$ were significant after FDR adjustment ( $a=0.0017$ ), namely $S$-GSH (M44) and $S$ - $\gamma$ GluCys (M43), consistent with the univariate analyses. Interestingly, the $S$-hCys cluster (M28 \& M29), which had been strongly associated with fuel type in univariate analyses (Table 2 and Figure 1B), did not detect the same associations after adjustment for $\mathrm{BaP}$ and age, both of which were marginally associated with $S$-hCys levels (Table 3). Also, the strong effects of fuel type and BaP on levels of the unannotated adduct, M30, (Table 2) were greatly reduced in the multivariable model, where only smokeless coal showed evidence of an association $(P$-value $=0.036)$.

\section{Discussion}

This is the first application of Cys34 adductomics to investigate populations exposed to high levels of combustion products that are known to contribute to lung disease. Indeed, nonsmoking women exposed to indoor emissions from smoky coal have among the highest lung cancer incidence and mortality in the world. ${ }^{5,}{ }^{6}$ Constituents of smoky coal and its emissions have been explored in an attempt to pinpoint those that account for lung cancer risk. ${ }^{7-10,25,26}$ Here, we integrated untargeted adductomics with external exposure measurements to investigate the influence of fuel type and external exposures on downstream biological processes that are reflected by Cys34 adducts.

The 50 T3-peptides detected in this study of Chinese women are similar to the 43 T3peptides reported by Grigoryan et al., ${ }^{23}$ who applied the same methodology to plasma from healthy smokers and nonsmokers in the U.S. The Venn diagram in Figure S3 (Supporting 
Information) compares the features reported from these two studies, 31 of which were detected in both. Grigoryan et al. ${ }^{23}$ reported that cigarette smokers had significantly higher levels of adducts representing Cys 34 addition of ethylene oxide and acrylonitrile (two constituents of cigarette smoke) as well as the T3-methylation product, and also had decreased levels of the Cys34 sulfinic acid and Cys34- $S$-Cys adduct. All of the women in the current study were nonsmokers, and a different set of adducts was identified that distinguished solid-fuel users from controls.

The most prominent class of Cys34 adducts detected in our investigation were the Cys34 mixed disulfides ( 22 of 50 T3 features in Table 1) that reflect reactions with low-molecularweight thiols. ${ }^{35}$ The median contributions of the five most abundant Cys34 disulfides are compared in Table S3 (Supporting Information) with those from targeted analysis of the same species in another investigation by Lepedda et al. ${ }^{36}$ The similar percentages derived from sets of independent data indicate that our Cys 34 adductomics pipeline is quantitatively reliable.

Several adducts detected in our study were significantly associated with the fuel type and $\mathrm{BaP}$ exposures. The strongest associations between adduct levels and fuel type involved the disulfides $S$-GSH (M44) and $S$ - $\gamma$-GluCys (M43) (Tables $2 \& 3$ ). Intracellular GSH plays a principle role in the elimination of reactive electrophiles, including ROS, and is depleted under oxidative stress. ${ }^{37,} 38$ The $S$-GSH adduct represents the reaction between Cys34 and GSH that can involve the unstable Cys34 sulfenic-acid (-SOH) as an intermediate. ${ }^{20}$ Thus, the lower levels of $S$-GSH observed in the solid-fuel groups relative to controls could reflect depletion of intracellular GSH that is mediated by exposures to reactive electrophiles generated by combustion products from solid fuels.

Using the estimated regression coefficients from multivariable models (Table 3), the fold change (control: exposed) for smoky coal $=1 / \exp (-1.4522)=4.27$ compared to 3.30 for wood and 2.49 for smokeless coal. This indicates that the $S$-GSH adduct was present at lower concentrations in smoky-coal users compared to smokeless-coal and wood-fuel users after adjustment for $\mathrm{BaP}$ exposure and age, and suggests that smoky coal may be a more potent cause of GSH depletion than either smokeless coal or wood.

Decreased levels of circulating GSH have been observed in various diseases and cancers, ${ }^{35}$ and the null genotype of glutathione $S$-transferase M1 was associated with increased lungcancer risk in Asian populations exposed to indoor combustion of coal, ${ }^{39}$ and smoky coal in Xuanwei County. ${ }^{13}$ Similar decreases in the $S$ - $\gamma$-GluCys adduct (Table 3) probably reflect the fact that $\gamma$-GluCys is a dipeptide precursor for the GSH tripeptide. ${ }^{40}$ Membrane-bound $\gamma$-glutamyltranspeptidase catabolizes conversion of extracellular GSH to CysGly, stimulating the production of pro-oxidant species, and is upregulated in various cancer cells and by depletion of intracellular GSH. ${ }^{38,40-42}$ It is interesting that the ratio of Cys34-SCysGly (M34) to Cys34-S-GSH (M44) was elevated in all exposed groups relative to controls (Figure 3 ), especially for smoky coal which showed a much stronger effect ( $P$-value $=0.0004)$ than for wood-fuel $(P$-value $=0.031)$ or smokeless coal $(P$-value $=0.034)$. This suggests that $\gamma$-glutamyltranspeptidase activity may have contributed to the decrease in circulating GSH via catabolism to CysGly, especially for subjects using smoky coal. 
One adduct that differed substantially across fuel types was the T3 labile adduct (M5) which has been reported previously. ${ }^{23}$ We suspect that this labile adduct disaggregates in the nanoelectrospray source because it has an accurate mass and MS2 spectrum identical to those of the unadducted T3 peptide but has a distinct retention time (eluting about $30 \mathrm{~s}$ earlier than the T3 peptide). Levels of this labile adduct were significantly lower in users of smoky coal compared to other fuel groups after adjustment for exposure to $\mathrm{BaP}$ and age but increased with exposure to $\mathrm{BaP}$ after adjusting for fuel type and age (Table 3). Although the identity of this adduct has not been ascertained, its levels were correlated with several Cys34 disulfides, particularly M17 ( $S$-mercaptoacetic acid) and the two isoforms of $S$-hCys (M28 \& M32). However, in our previous adductomic analysis we observed that this labile T3 adduct was not affected by TCEP treatment, suggesting that it is not a Cys34 disulfide. ${ }^{23}$

Further research is required to annotate a number of adducts that were associated with exposure to combustion products, particularly the labile T3 adduct (M5) and M30 (likely composition, $+\mathrm{C}_{4} \mathrm{H}_{9} \mathrm{O}_{3} \mathrm{~S}$ ). Also, the relationship between levels of $S$-hCys (M28+M29) and solid-fuel, which was highly significant in univariate analyses (Table 2) but not in the multivariable model (Table 3), requires additional investigation.

In summary, our study detected a host of HSA adducts in plasma from 39 nonsmoking Chinese women. Several of these adducts were significantly influenced by solid-fuel use and pollutant exposures, particularly $S$-GSH and $S$ - $\gamma$-GluCys, which were both present at lower levels in subjects using solid fuels than in controls (Tables $2 \& 3$ ). We realize that this study is small and will require validation with larger samples sizes. Another limitation is the lack of measurements of $\mathrm{PM}_{2.5}$ and $\mathrm{BaP}$ exposures among control subjects, although it is reasonable to expect that nonsmoking controls who used electricity/gas had lower exposures to $\mathrm{PM}_{2.5}$ and $\mathrm{BaP}$ than the solid-fuel users.

\section{Supplementary Material}

Refer to Web version on PubMed Central for supplementary material.

\section{Acknowledgments}

This work was supported by grant R33CA191159 and by the intramural program of the National Cancer Institute of the U.S. National Institutes of Health. The authors also acknowledge support from grants U54ES016115 and R44ES022360 from the National Institute for Environmental Health Sciences. The content is solely the responsibility of the authors and does not necessarily represent the official views of the National Institutes of Health.

\section{ABBREVIATIONS}

$\begin{array}{ll}\text { BaP } & \text { benzo }(\text { a)pyrene } \\ \text { CV } & \text { coefficient of variation } \\ \text { CysGly } & \text { cysteinylglycine } \\ \text { FDR } & \text { false discovery rate } \\ \boldsymbol{\gamma} \text {-GluCys } & \boldsymbol{\gamma} \text {-glutamylcysteine }\end{array}$




$\begin{array}{ll}\text { GSH } & \text { glutathione } \\ \text { hCys } & \text { homocysteine } \\ \text { HK } & \text { "housekeeping peptide" } \\ \text { HRMS } & \text { high-resolution mass spectrometry } \\ \text { HSA } & \text { human serum albumin } \\ \text { IAA-iT3 } & \text { carbamidomethylated iT3 peptide internal standard } \\ \text { ICC } & \text { intraclass correlation } \\ \text { iT3 } & \text { isotopically labeled T3 peptide } \\ \text { MIM } & \text { monoisotopic mass } \\ \text { nLC } & \text { nanoflow liquid chromatography } \\ \text { PAH } & \text { polycyclic aromatic hydrocarbon } \\ \text { PM } & \text { particulate matter } \\ \text { PM } & \text { particulate matter with aerodynamic diameter less than } 2.5 \mu \text { m } \\ r_{S} & \text { Spearman correlation coefficient } \\ \text { ROS } & \text { reactive oxygen species } \\ \text { RT } & \text { retention time } \\ \text { T3 } & \text { third largest peptide after tryptic digestion of HSA which includes Cys34 }\end{array}$

\section{References}

1. Torre LA, Bray F, Siegel RL, Ferlay J, Lortet-Tieulent J, Jemal A. Global cancer statistics, 2012. CA: a cancer journal for clinicians. 2015; 65(2):87-108. [PubMed: 25651787]

2. Sun S, Schiller JH, Gazdar AF. Lung cancer in never smokers-a different disease. Nat Rev Cancer. 2007; 7(10):778-90. [PubMed: 17882278]

3. Hosgood HD 3rd, Boffetta P, Greenland S, Lee YC, McLaughlin J, Seow A, Duell EJ, Andrew AS, Zaridze D, Szeszenia-Dabrowska N, Rudnai P, Lissowska J, Fabianova E, Mates D, Bencko V, Foretova L, Janout V, Morgenstern H, Rothman N, Hung RJ, Brennan P, Lan Q. In-home coal and wood use and lung cancer risk: a pooled analysis of the International Lung Cancer Consortium. Environ Health Perspect. 2010; 118(12):1743-7. [PubMed: 20846923]

4. Smith KR, Bruce N, Balakrishnan K, Adair-Rohani H, Balmes J, Chafe Z, Dherani M, Hosgood HD, Mehta S, Pope D, Rehfuess E, Group, H. C. R. E. Millions dead: how do we know and what does it mean? Methods used in the comparative risk assessment of household air pollution. Annu Rev Public Health. 2014; 35:185-206. [PubMed: 24641558]

5. Barone-Adesi F, Chapman RS, Silverman DT, He X, Hu W, Vermeulen R, Ning B, Fraumeni JF Jr, Rothman N, Lan Q. Risk of lung cancer associated with domestic use of coal in Xuanwei, China: retrospective cohort study. Bmj. 2012; 345:e5414. [PubMed: 22936785]

6. Mumford JL, He XZ, Chapman RS, Cao SR, Harris DB, Li XM, Xian YL, Jiang WZ, Xu CW, Chuang JC, Wilson WE, Cooke M. Lung-Cancer and Indoor Air-Pollution in Xuan-Wei, China. Science. 1987; 235(4785):217-220. [PubMed: 3798109] 
7. Lan Q, He X, Shen M, Tian L, Liu LZ, Lai H, Chen W, Berndt SI, Hosgood HD, Lee KM, Zheng T, Blair A, Chapman RS. Variation in lung cancer risk by smoky coal subtype in Xuanwei, China. International journal of cancer Journal international du cancer. 2008; 123(9):2164-9. [PubMed: 18712724]

8. Hu W, Downward GS, Reiss B, Xu J, Bassig BA, Hosgood HD 3rd, Zhang L, Seow WJ, Wu G, Chapman RS, Tian L, Wei F, Vermeulen R, Lan Q. Personal and indoor M25 exposure from burning solid fuels in vented and unvented stoves in a rural region of China with a high incidence of lung cancer. Environmental science \& technology. 2014; 48(15):8456-64. [PubMed: 25003800]

9. Downward GS, Hu W, Rothman N, Reiss B, Wu G, Wei F, Chapman RS, Portengen L, Qing L, Vermeulen R. Polycyclic aromatic hydrocarbon exposure in household air pollution from solid fuel combustion among the female population of Xuanwei and Fuyuan counties, China. Environmental science \& technology. 2014; 48(24):14632-41. [PubMed: 25393345]

10. Downward GS, Hu W, Large D, Veld H, Xu J, Reiss B, Wu G, Wei F, Chapman RS, Rothman N, Qing L, Vermeulen R. Heterogeneity in coal composition and implications for lung cancer risk in Xuanwei and Fuyuan counties, China. Environment international. 2014; 68:94-104. [PubMed: 24721117]

11. Mumford JL, Lee X, Lewtas J, Young TL, Santella RM. DNA adducts as biomarkers for assessing exposure to polycyclic aromatic hydrocarbons in tissues from Xuan Wei women with high exposure to coal combustion emissions and high lung cancer mortality. Environ Health Perspect. 1993; 99:83-7. [PubMed: 8319664]

12. Hosgood HD 3rd, Pao W, Rothman N, Hu W, Pan YH, Kuchinsky K, Jones KD, Xu J, Vermeulen R, Simko J, Lan Q. Driver mutations among never smoking female lung cancer tissues in China identify unique EGFR and KRAS mutation pattern associated with household coal burning. Respiratory medicine. 2013; 107(11):1755-62. [PubMed: 24055406]

13. Lan Q, He X, Costa DJ, Tian L, Rothman N, Hu G, Mumford JL. Indoor coal combustion emissions, GSTM1 and GSTT1 genotypes, and lung cancer risk: a case-control study in Xuan Wei, China. Cancer Epidemiol Biomarkers Prev. 2000; 9(6):605-8. [PubMed: 10868696]

14. Lan Q, Mumford JL, Shen M, Demarini DM, Bonner MR, He X, Yeager M, Welch R, Chanock S, Tian L, Chapman RS, Zheng T, Keohavong P, Caporaso N, Rothman N. Oxidative damage-related genes AKR1C3 and OGG1 modulate risks for lung cancer due to exposure to PAH-rich coal combustion emissions. Carcinogenesis. 2004; 25(11):2177-81. [PubMed: 15284179]

15. Miller EC, Miller JA. Mechanisms of chemical carcinogenesis: nature of proximate carcinogens and interactions with macromolecules. Pharmacol Rev. 1966; 18(1):805-38. [PubMed: 5325210]

16. Brodie BB, Reid WD, Cho AK, Sipes G, Krishna G, Gillette JR. Possible mechanism of liver necrosis caused by aromatic organic compounds. Proc Natl Acad Sci U S A. 1971; 68(1):160-4. [PubMed: 4395686]

17. Go YM, Jones DP. The redox proteome. J Biol Chem. 2013; 288(37):26512-20. [PubMed: 23861437]

18. Rubino FM, Pitton M, Di Fabio D, Colombi A. Toward an "omic" physiopathology of reactive chemicals: thirty years of mass spectrometric study of the protein adducts with endogenous and xenobiotic compounds. Mass Spectrom Rev. 2009; 28(5):725-84. [PubMed: 19127566]

19. Aldini G, Vistoli G, Regazzoni L, Gamberoni L, Facino RM, Yamaguchi S, Uchida K, Carini M. Albumin is the main nucleophilic target of human plasma: a protective role against pro-atherogenic electrophilic reactive carbonyl species? Chem Res Toxicol. 2008; 21(4):824-35. [PubMed: 18324789]

20. Carballal S, Alvarez B, Turell L, Botti H, Freeman BA, Radi R. Sulfenic acid in human serum albumin. Amino acids. 2007; 32(4):543-51. [PubMed: 17061035]

21. Aldini, G., Yeum, KJ., Vistoli, G. Covalent Modifications of Albumin Cys34 as a Biomarker of Mild Oxidative Stress. In: Aldini, G.Yeum, K-J.Niki, E., Russell, RM., editors. Biomarkers for Antioxidant Defense and Oxidative Damage: Principles and Practical Applications. WileyBlackwell; 2010. p. 229-241.

22. Nagumo K, Tanaka M, Chuang VT, Setoyama H, Watanabe H, Yamada N, Kubota K, Tanaka M, Matsushita K, Yoshida A, Jinnouchi H, Anraku M, Kadowaki D, Ishima Y, Sasaki Y, Otagiri M, Maruyama T. Cys34-cysteinylated human serum albumin is a sensitive plasma marker in oxidative stress-related chronic diseases. PLoS One. 2014; 9(1):e85216. [PubMed: 24416365] 
23. Grigoryan H, Edmands W, Lu SS, Yano Y, Regazzoni L, Iavarone AT, Williams ER, Rappaport SM. Adductomics Pipeline for Untargeted Analysis of Modifications to Cys34 of Human Serum Albumin. Anal Chem. 2016; 88(21):10504-10512. [PubMed: 27684351]

24. Grigoryan H, Li H, Iavarone AT, Williams ER, Rappaport SM. Cys34 adducts of reactive oxygen species in human serum albumin. Chem Res Toxicol. 2012; 25(8):1633-42. [PubMed: 22591159]

25. Hosgood HD, Vermeulen R, Wei H, Reiss B, Coble J, Wei F, Jun X, Wu G, Rothman N, Lan Q. Combustion-derived nanoparticle exposure and household solid fuel use in Xuanwei and Fuyuan, China. Int J Environ Health Res. 2012; 22(6):571-81. [PubMed: 22639822]

26. Seow WJ, Hu W, Vermeulen R, Hosgood HD Iii, Downward GS, Chapman RS, He X, Bassig BA, Kim C, Wen C, Rothman N, Lan Q. Household air pollution and lung cancer in China: a review of studies in Xuanwei. Chinese journal of cancer. 2014; 33(10):471-5. [PubMed: 25223911]

27. Chambers MC, Maclean B, Burke R, Amodei D, Ruderman DL, Neumann S, Gatto L, Fischer B, Pratt B, Egertson J, Hoff K, Kessner D, Tasman N, Shulman N, Frewen B, Baker TA, Brusniak MY, Paulse C, Creasy D, Flashner L, Kani K, Moulding C, Seymour SL, Nuwaysir LM, Lefebvre B, Kuhlmann F, Roark J, Rainer P, Detlev S, Hemenway T, Huhmer A, Langridge J, Connolly B, Chadick T, Holly K, Eckels J, Deutsch EW, Moritz RL, Katz JE, Agus DB, MacCoss M, Tabb DL, Mallick P. A cross-platform toolkit for mass spectrometry and proteomics. Nat Biotechnol. 2012; 30(10):918-20. [PubMed: 23051804]

28. Team, RC. R: A language and environment for statistical computing. R Foundation for Statistical Computing; Vienna, Austria: 2014.

29. Patiny L, Borel A. ChemCalc: a building block for tomorrow's chemical infrastructure. J Chem Inf Model. 2013; 53(5):1223-8. [PubMed: 23480664]

30. Wolf S, Schmidt S, Muller-Hannemann M, Neumann S. In silico fragmentation for computer assisted identification of metabolite mass spectra. BMC Bioinformatics. 2010; 11:148. [PubMed: 20307295]

31. Benjamini Y, Hochberg Y. Controlling the False Discovery Rate: a Practical and Powerful Approach to Multiple Testing. Journal of the Royal Statistical Society. 1995; 57(1):289-300.

32. Newson R. SMILEPLOT: Stata module to create plots for use with multiple significance tests. Statistical Software Components. 2012

33. Dinno A. dunntest: Dunn's test of multiple comparisons using rank sums. 2014

34. Shannon P, Markiel A, Ozier O, Baliga NS, Wang JT, Ramage D, Amin N, Schwikowski B, Ideker T. Cytoscape: a software environment for integrated models of biomolecular interaction networks. Genome Res. 2003; 13(11):2498-504. [PubMed: 14597658]

35. Isokawa M, Kanamori T, Funatsu T, Tsunoda M. Analytical methods involving separation techniques for determination of low-molecular-weight biothiols in human plasma and blood. $\mathrm{J}$ Chromatogr B Analyt Technol Biomed Life Sci. 2014; 964:103-15.

36. Lepedda AJ, Zinellu A, Nieddu G, De Muro P, Carru C, Spirito R, Guarino A, Piredda F, Formato M. Human serum albumin Cys34 oxidative modifications following infiltration in the carotid atherosclerotic plaque. Oxid Med Cell Longev. 2014; 2014:690953. [PubMed: 24738021]

37. Nel A. Atmosphere. Air pollution-related illness: effects of particles. Science. 2005; 308(5723): 804-6. [PubMed: 15879201]

38. Pompella A, Visvikis A, Paolicchi A, De Tata V, Casini AF. The changing faces of glutathione, a cellular protagonist. Biochemical pharmacology. 2003; 66(8):1499-503. [PubMed: 14555227]

39. Hosgood HD, Berndt SI, Lan Q. GST genotypes and lung cancer susceptibility in Asian populations with indoor air pollution exposures: A meta-analysis. Mutation Research-Reviews in Mutation Research. 2007; 636(1-3):134-143. [PubMed: 17428724]

40. Lu SC. Glutathione synthesis. Biochimica et biophysica acta. 2013; 1830(5):3143-53. [PubMed: 22995213]

41. Pompella A, De Tata V, Paolicchi A, Zunino F. Expression of gamma-glutamyltransferase in cancer cells and its significance in drug resistance. Biochemical pharmacology. 2006; 71(3):231-8. [PubMed: 16303117]

42. Dominici S, Paolicchi A, Lorenzini E, Maellaro E, Comporti M, Pieri L, Minotti G, Pompella A. Gamma-glutamyltransferase-dependent prooxidant reactions: a factor in multiple processes. Biofactors. 2003; 17(1-4):187-98. [PubMed: 12897440] 

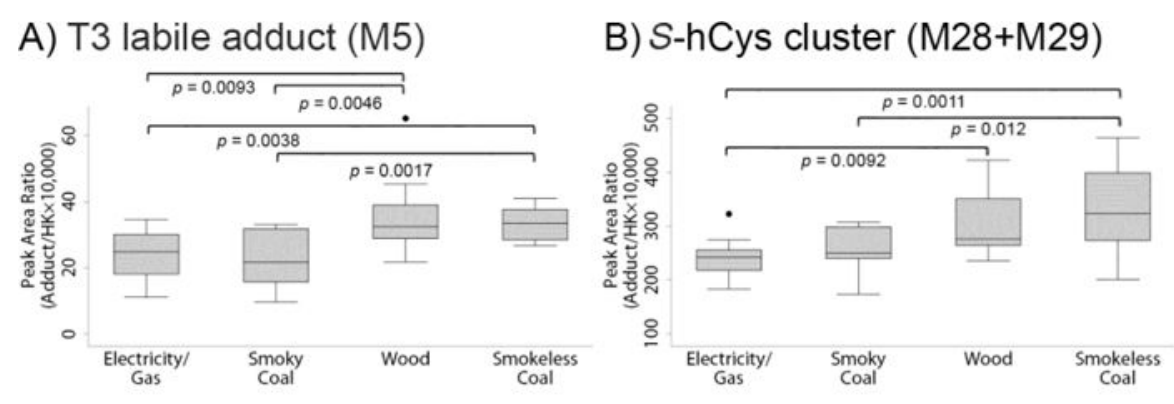

E) S-GSH (M44)

D) S-y-GluCys (M43)
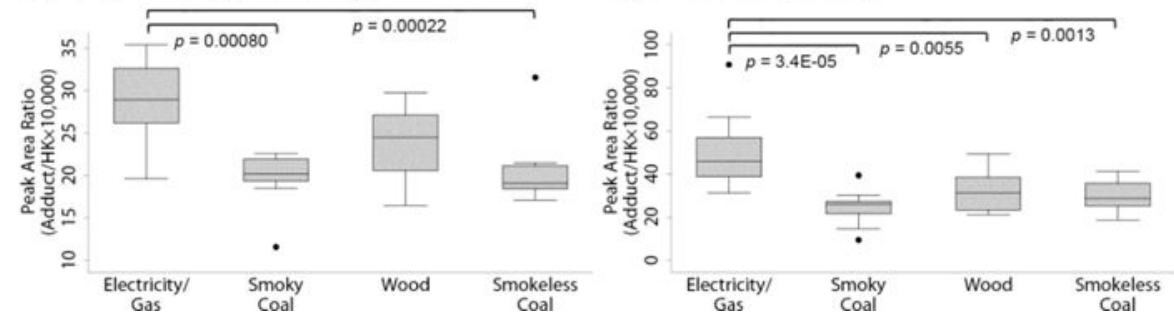

C) Unknown Cys34 adduct (M30)

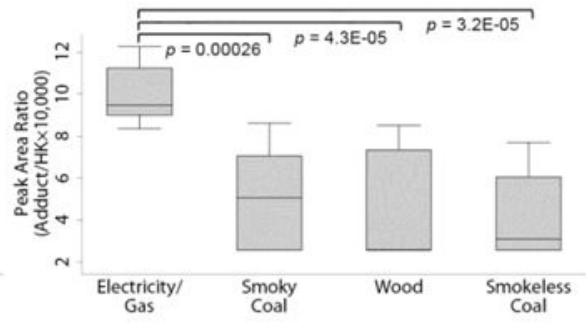

\section{Figure 1.}

Pairwise comparisons of adducts showing significant global differences across fuel groups by Kruskal-Wallis tests (Table 2): (A) the labile T3 adduct (M5), (B) the $S$-hCys cluster, (C) a Cys34 adduct with unknown annotation (M30), (D) $S$ - $\gamma$-GluCys (M43) and (E) $S$-GSH (M44). $P$-values indicate significant Wilcoxon rank sum tests after correction for multiple testing. 


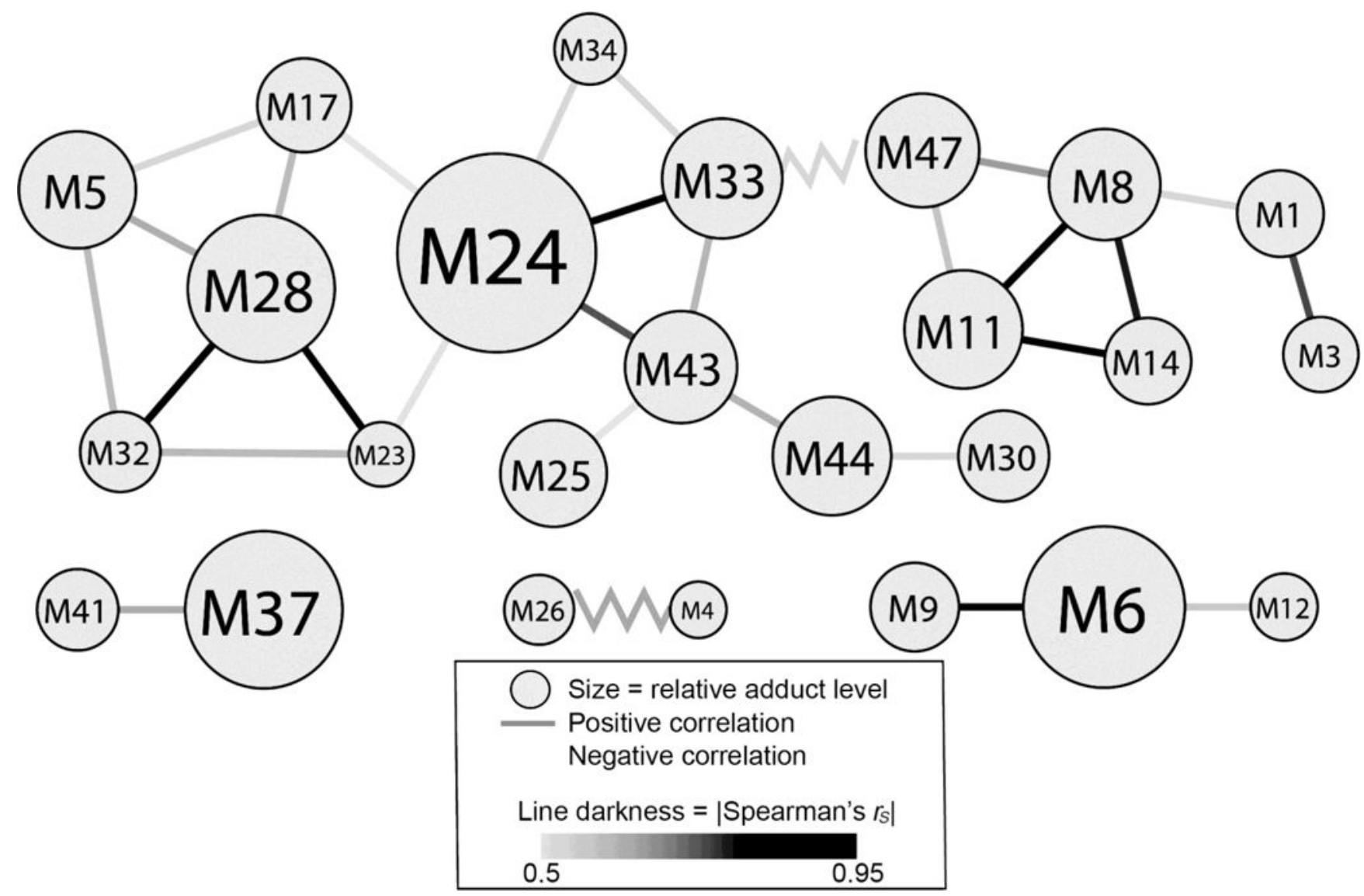

Figure 2.

Map displaying adducts with moderate to very strong Spearman correlations $\left(\left|r_{S}\right|>0.5\right)$. Each adduct is represented by a circle, whose area is linearly related to the median logged adduct level. Each correlation is represented by a line, whose darkness corresponds to the strength of correlation. 


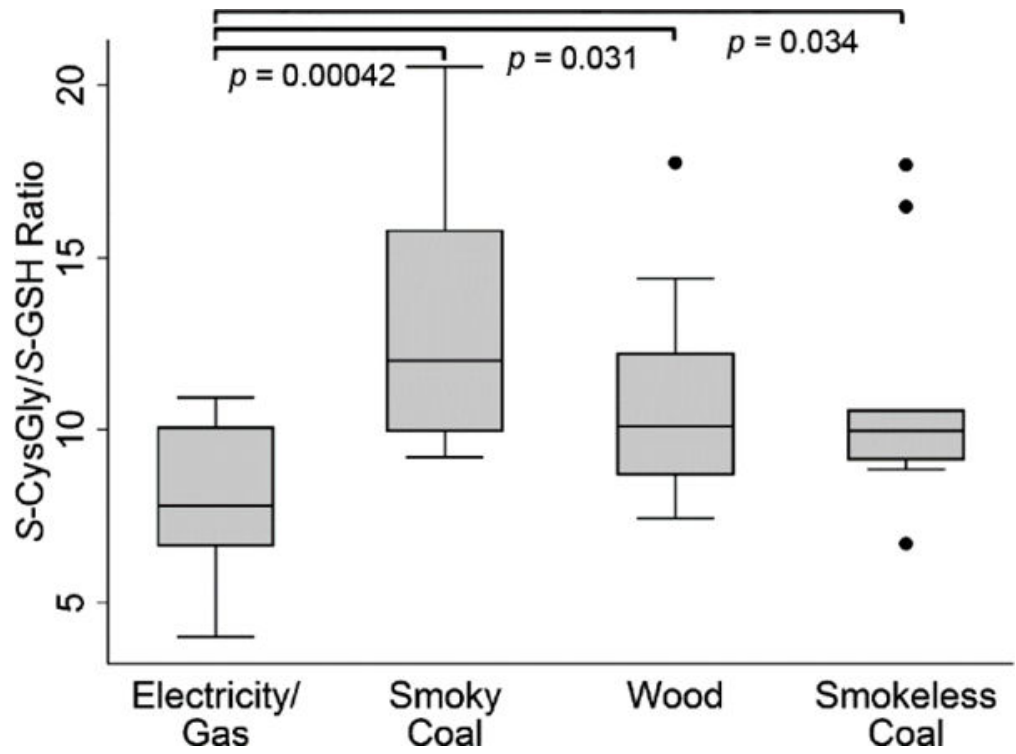

Figure 3.

Pairwise comparisons of ratios of $S$-CysGly (M37+M40+M41) to $S$-GSH (M44) across fuel groups (Kruskal-Wallis, $P$-value $=0.0107$ ). 


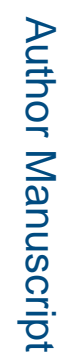

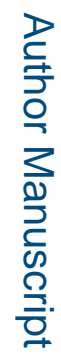

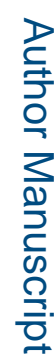

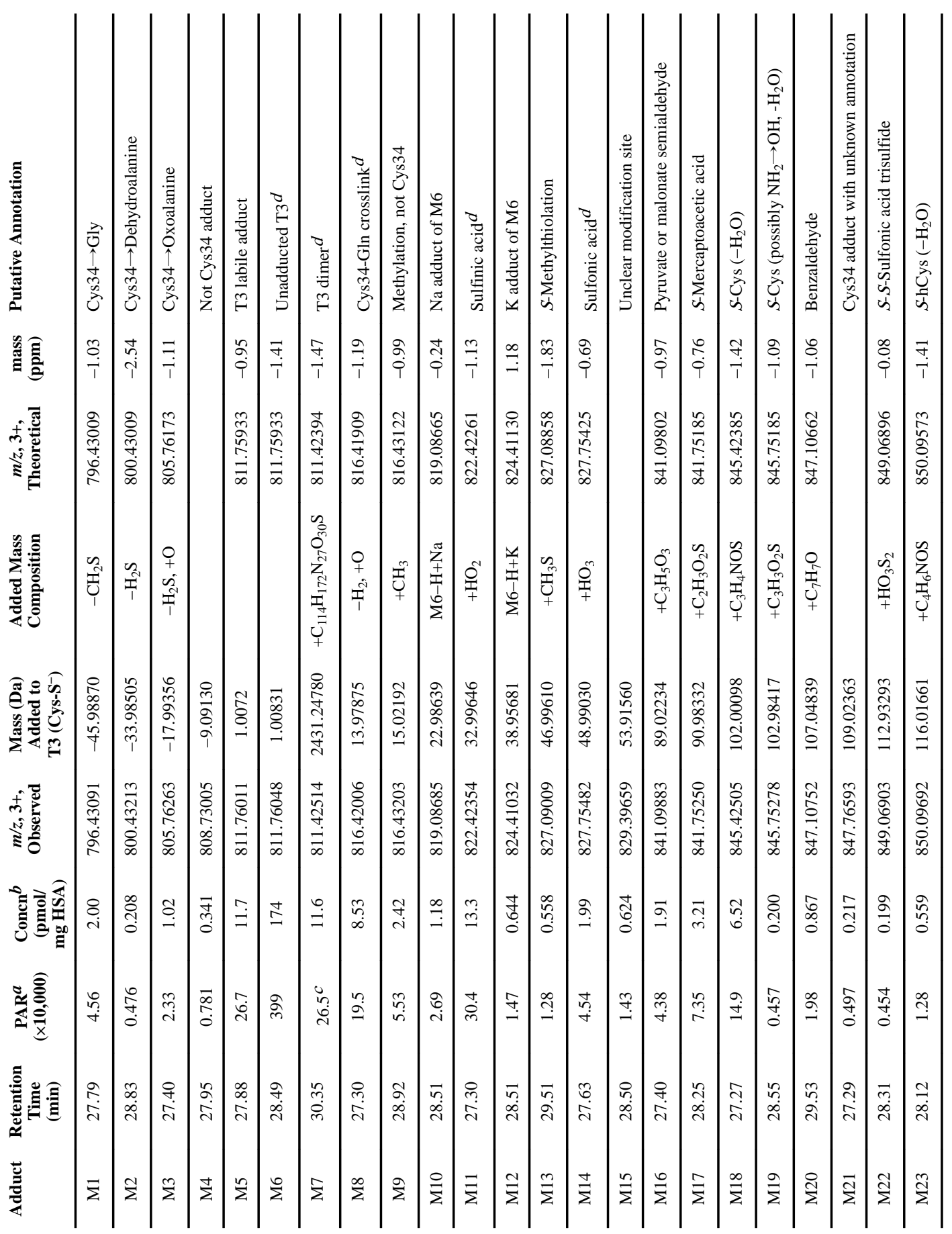




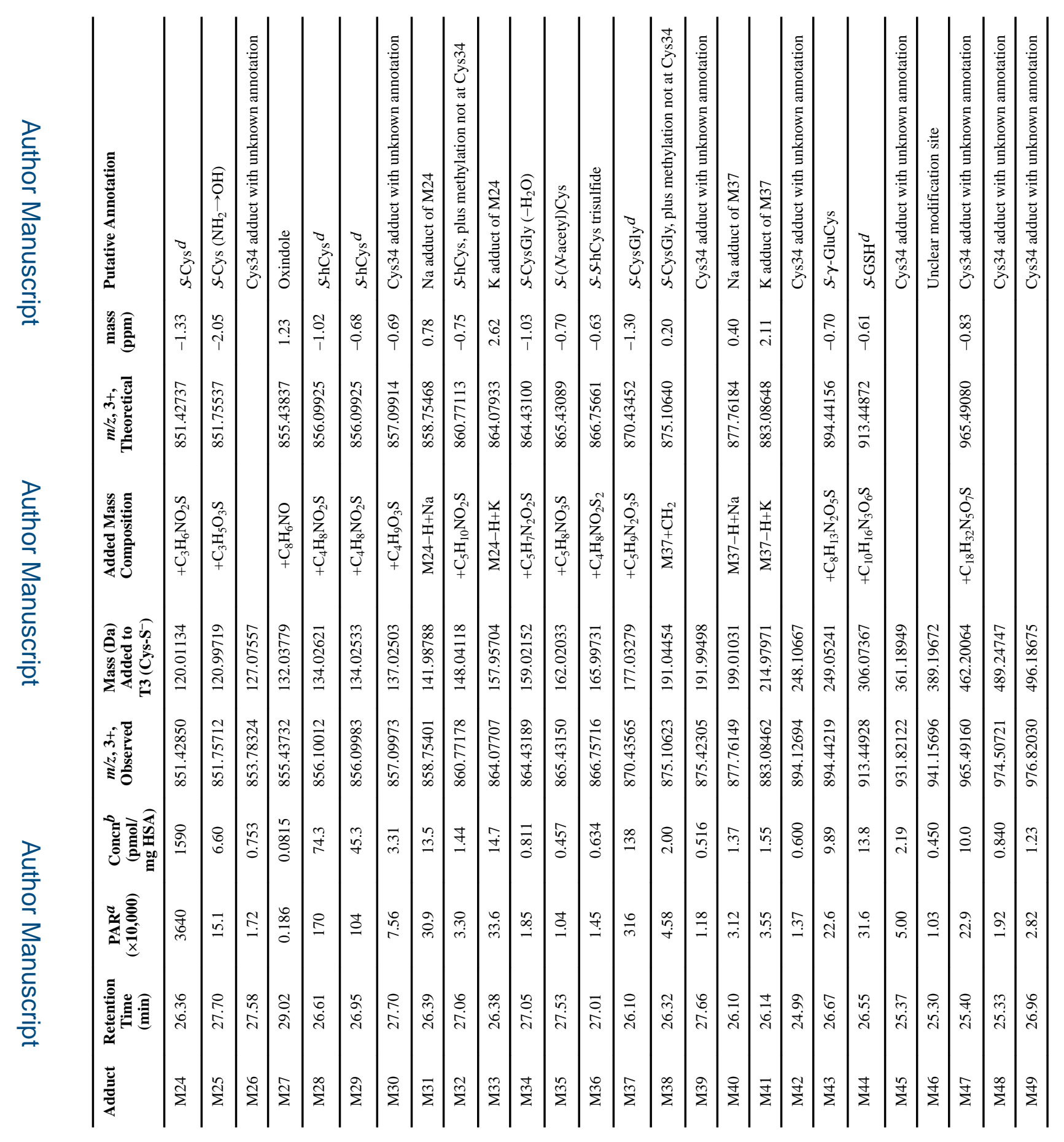

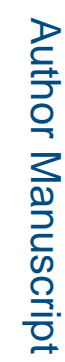




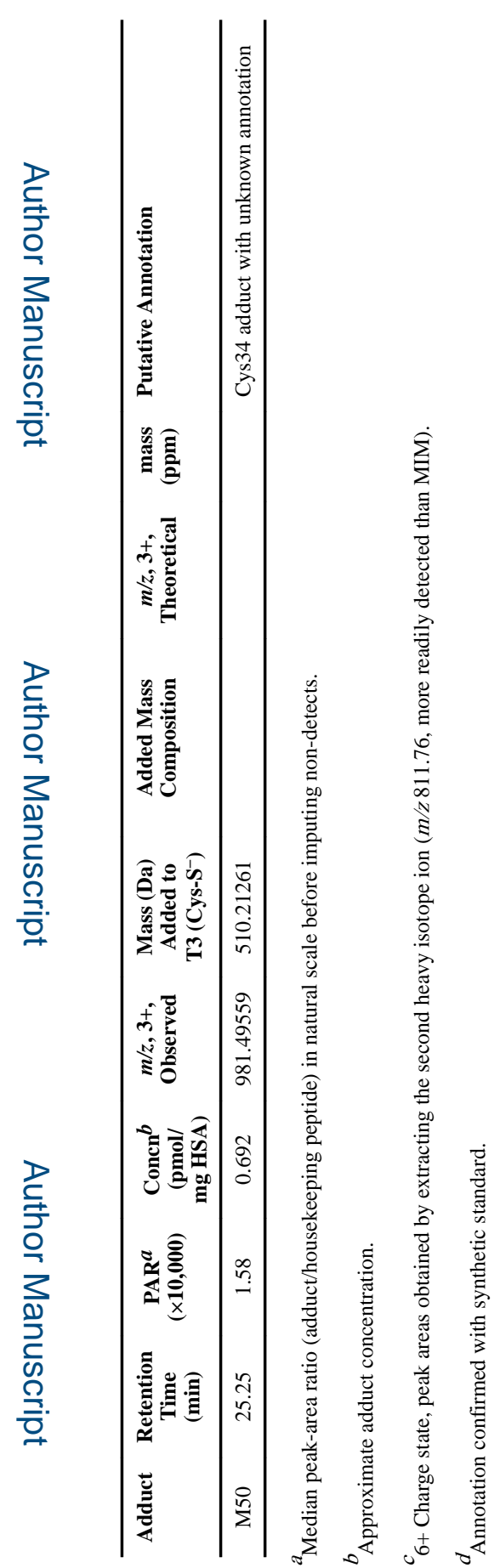

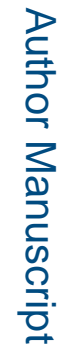




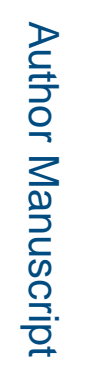

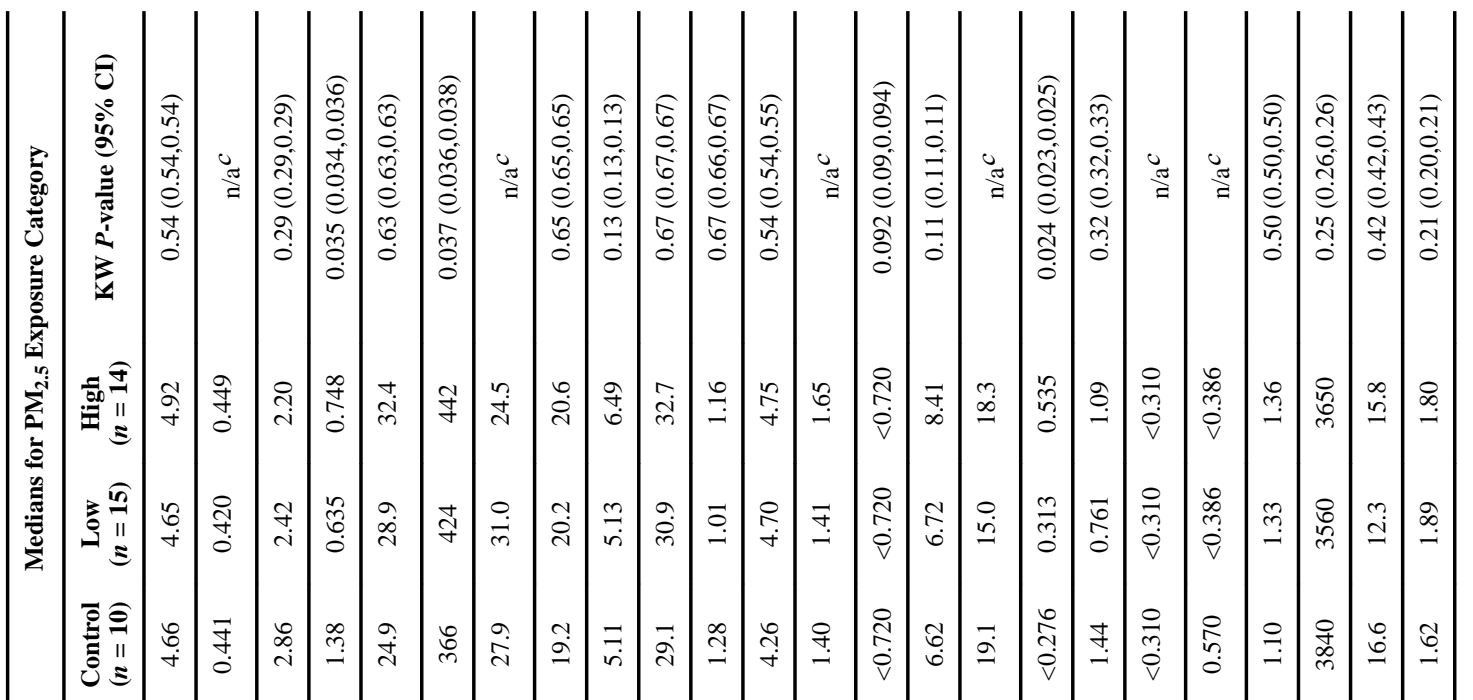

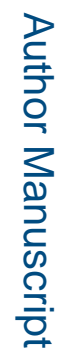

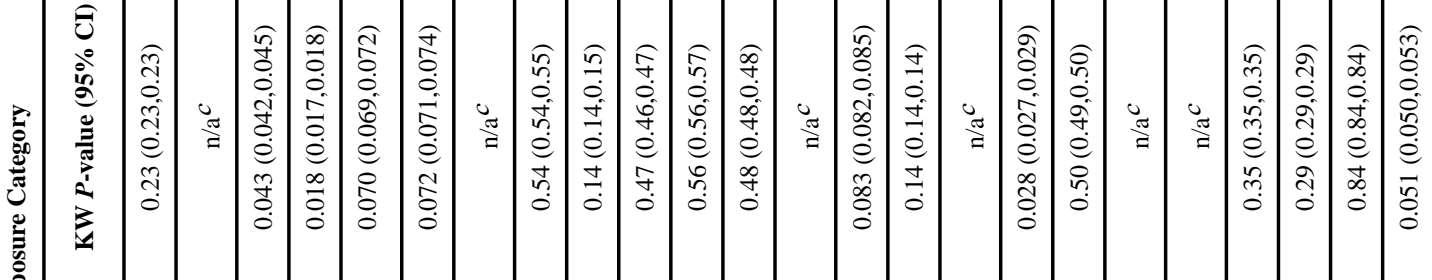

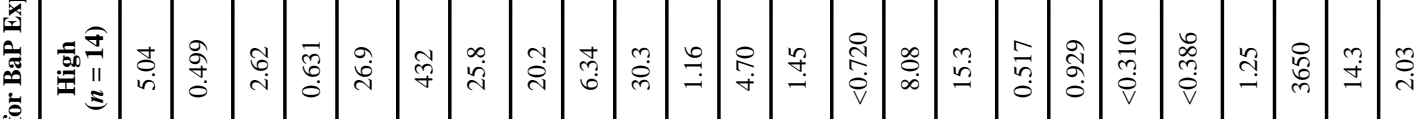

?

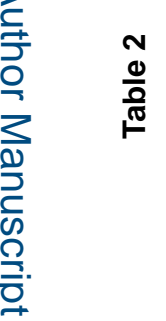

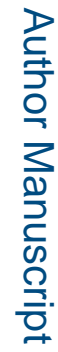

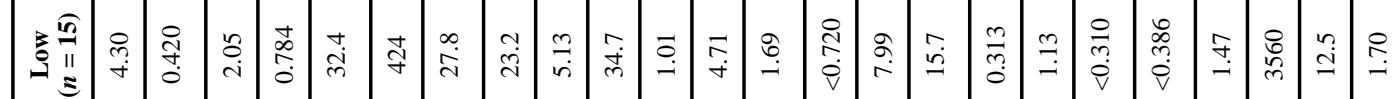
至至

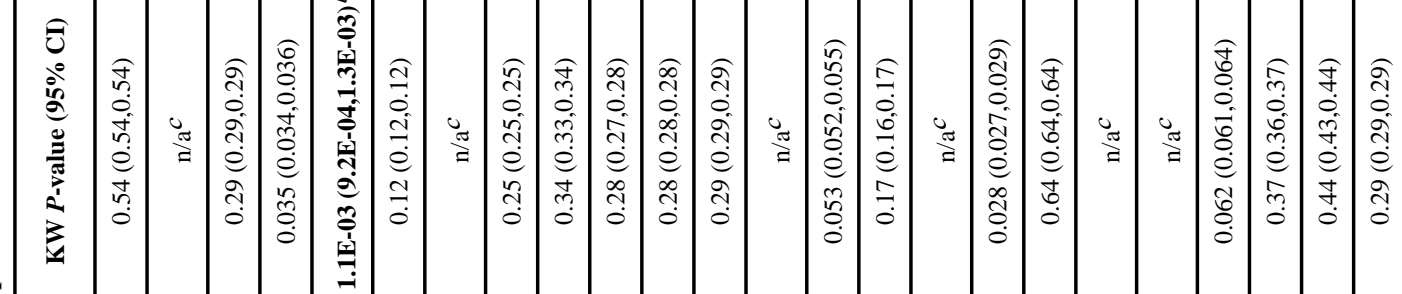
.

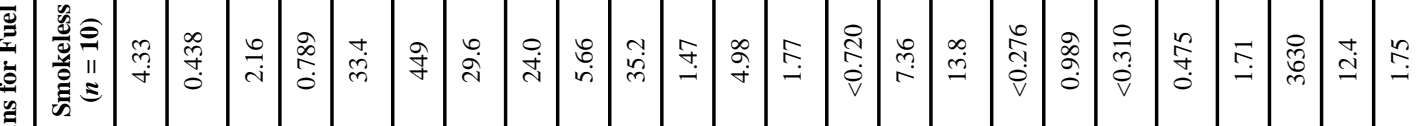

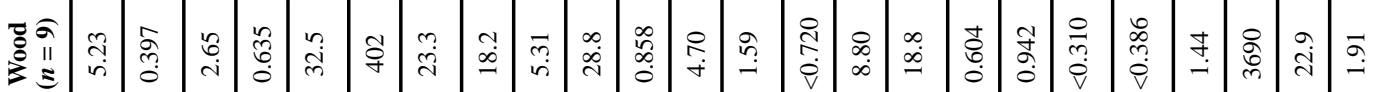
竞至

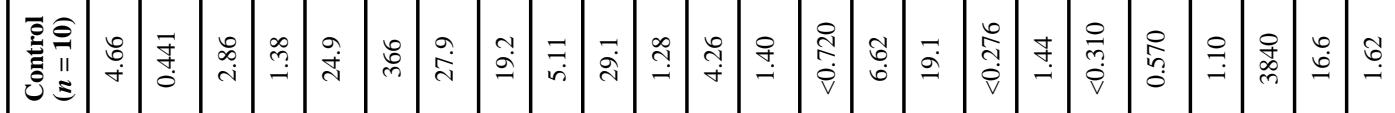

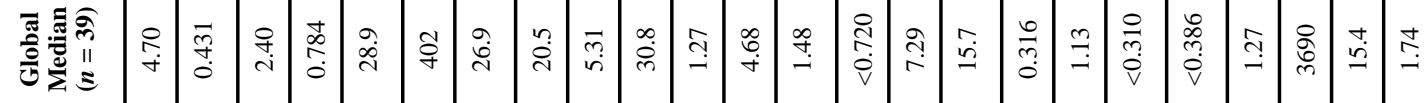

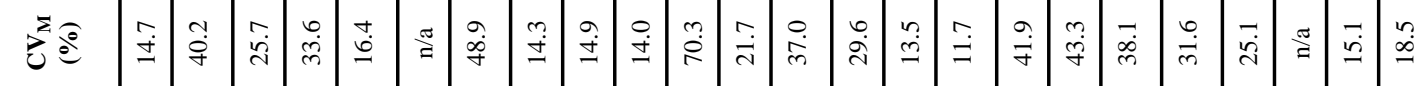

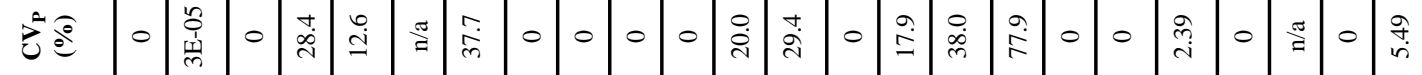
这

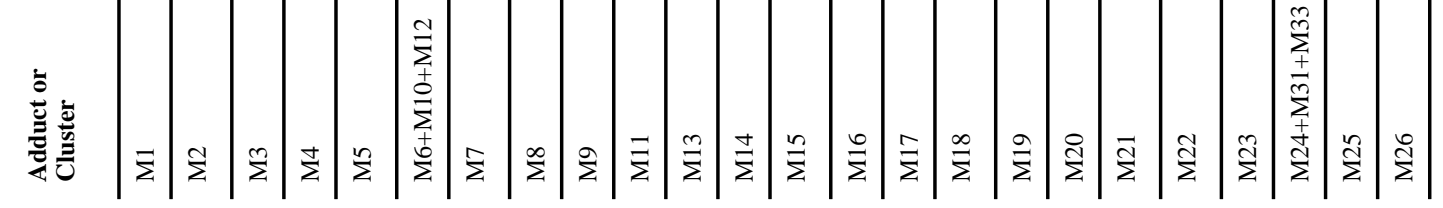




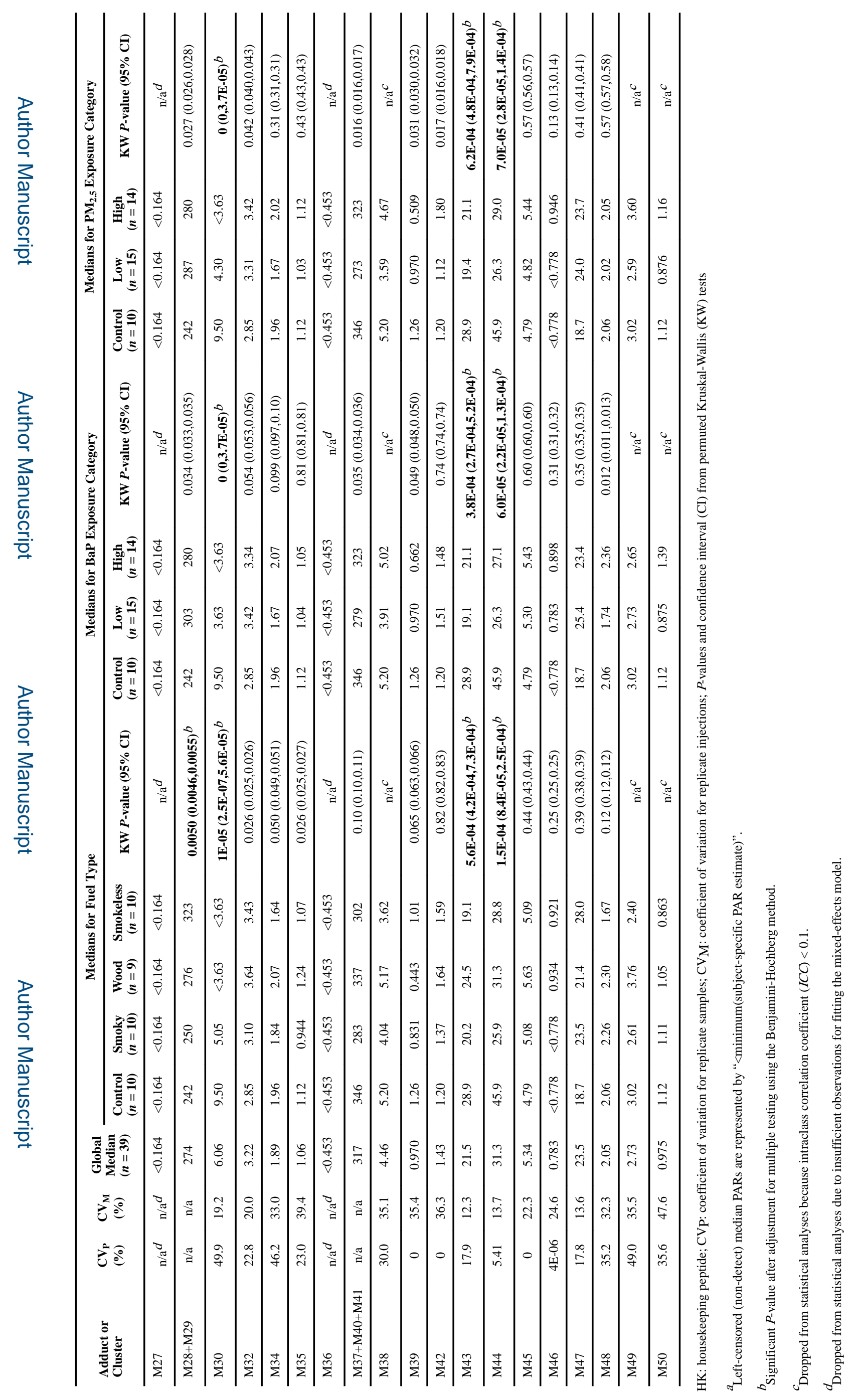




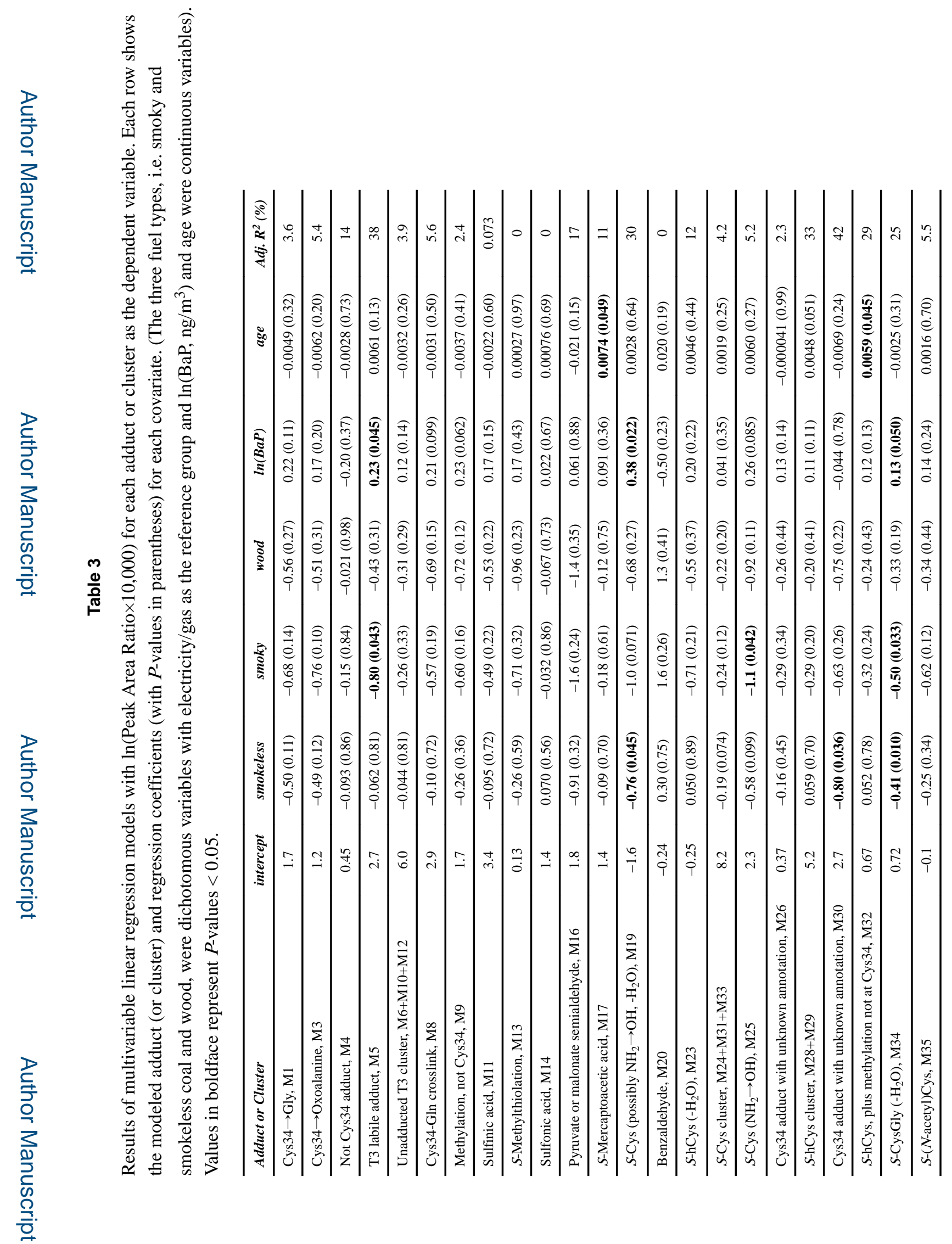

Environ Sci Technol. Author manuscript; available in PMC 2017 August 23. 


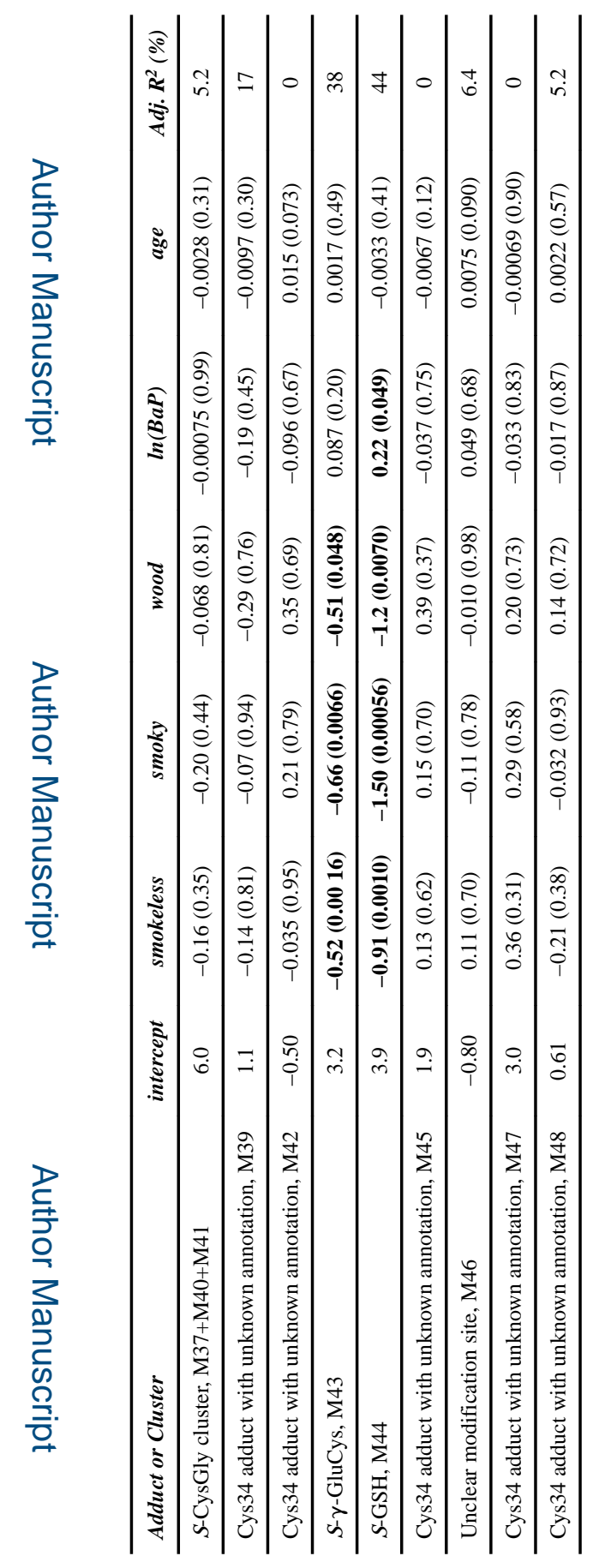

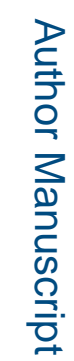

